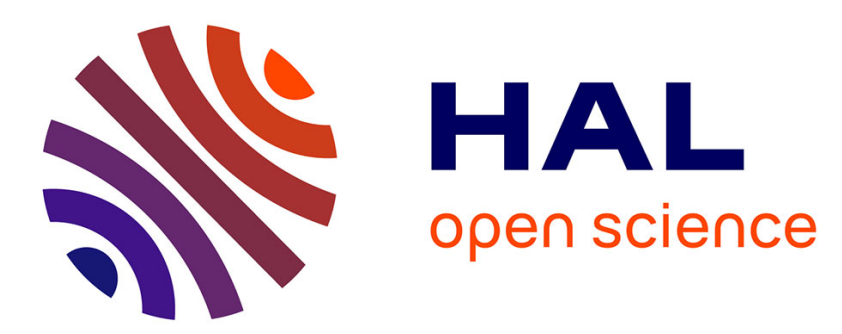

\title{
A new quasi-invariant parameter characterizing the postural alignment of young asymptomatic adults
}

Célia Amabile, Hélène Pillet, Virginie Lafage, Cédric Barrey, Jean-Marc Vital, Wafa Skalli

\section{- To cite this version:}

Célia Amabile, Hélène Pillet, Virginie Lafage, Cédric Barrey, Jean-Marc Vital, et al.. A new quasiinvariant parameter characterizing the postural alignment of young asymptomatic adults. European Spine Journal, 2016, 25 (11), pp.3666-3674. 10.1007/s00586-016-4552-y · hal-02460911

\section{HAL Id: hal-02460911 \\ https://hal.science/hal-02460911}

Submitted on 7 Feb 2020

HAL is a multi-disciplinary open access archive for the deposit and dissemination of scientific research documents, whether they are published or not. The documents may come from teaching and research institutions in France or abroad, or from public or private research centers.
L'archive ouverte pluridisciplinaire HAL, est destinée au dépôt et à la diffusion de documents scientifiques de niveau recherche, publiés ou non, émanant des établissements d'enseignement et de recherche français ou étrangers, des laboratoires publics ou privés. 


\title{
A new quasi-invariant parameter characterizing the postural alignment of young asymptomatic adults
}

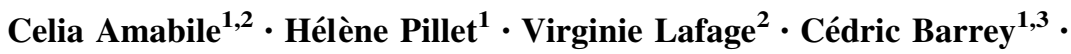 \\ Jean-Marc Vital ${ }^{4} \cdot$ Wafa Skalli $^{1}$
}

\begin{abstract}
Purpose Our study aims to describe the postural alignment of young asymptomatic subjects from head to feet from bi-planar standing full-body X-rays, providing database to compare to aging adults. Novelty resides in the inclusion of the head and lower limbs in the erected posture's analysis.

Methods For 69 young asymptomatic subjects (18-40 years old) 3D reconstructions of the head, spine, pelvis and lower limbs segments were performed from biplanar full-body X-rays. Usual studied spinal, pelvic and lower limbs' parameters were computed in 3D, sagittal and frontal planes of the patient. Relationships between these parameters were investigated. Inclinations of different lines were studied to characterize the erected posture.

Results Values found for spinal curvatures, pelvic parameters and lower limbs geometrical parameters agreed with the literature: thoracic kyphosis, lumbar lordosis, pelvic incidence, pelvic tilt and sagittal vertical axis were respectively in average of $26.9^{\circ}\left(\mathrm{SD} 7.2^{\circ}\right), 30.5^{\circ}\left(\mathrm{SD} 7.5^{\circ}\right)$, $51.0^{\circ}\left(\mathrm{SD} 9.4^{\circ}\right), 11.1^{\circ}\left(\mathrm{SD} 5.6^{\circ}\right)$ and $-8.9 \mathrm{~mm}$ (SD
\end{abstract}

Celia Amabile

celia.amabile@ensam.eu

1 Arts et Métiers ParisTech, LBM/Institut de Biomécanique Humaine Georges Charpak, 151 bd de l'Hôpital, 75013 Paris, France

2 Spine Service, Hospital for Special Surgery, 535 East 70th Street, Belaire 4-E, New York, NY 10021, USA

3 Department of Neurosurgery and Spine Surgery, P Wertheimer Hospital, Hospices Civils de Lyon, University Claude Bernard Lyon 1, 59 Boulevard Pinel, 69003 Lyon, France

4 Department of Orthopaedics and Spine Surgery, University Hospital of Bordeaux, Bordeaux, France
$21.6 \mathrm{~mm}$ ). The angle between the vertical and the line joining the most superior point of dentiform apophyse of $\mathrm{C} 2$ (OD) and the center of the bi-coxofemoral axis (HA) was the less variable one (SD 1.6 $6^{\circ}$.

Conclusions This study on 3D postural alignment reports the geometry of the spine, pelvis and lower limbs, of the young asymptomatic adult. The less variable angle is the one of the line OD-HA with the vertical, highlighting the vertical alignment of the head above the pelvis. This study provides a basis for future comparisons when investigating aging populations.

Keywords Skeleton's postural alignment - 3D · Asymptomatic young adults $\cdot$ Head to feet $\cdot$ Spinal alignment

\section{Introduction}

Dubousset first introduced the concept of the "conus of economy" describing the economic standing posture [1]. Failure to maintain the center of gravity in this conus would trigger compensatory mechanisms to restore a stable posture. Postural alignment is maintained to stay in this "conus of economy": alignment of all segments above the pelvis (torso and head) is needed to provide the best posture at the least energy expense. Particularly, keeping the head aligned with the whole body is important to provide horizontal gaze, but also accurate sensory inputs (i.e. inner ear). Adding that the head weight is approximately 4 to $5 \mathrm{~kg}$ [2], its global position in space appears of prior importance when considering posture and balance.

However, during aging, degradation of the musculoskeletal system, due to disc degeneration, osteoporosis and loss of muscular volume, contributes to the degradation of 
postural alignment, leading to potential severe osteoarticular damages [3]. In addition, postural malalignment increases the risk of loss of balance and fall that are associated to societal costs (for example, US\$17,483 mean cost of hospitalization for fall-related injury in the US [4]). To maintain this postural alignment, different strategies, involving the whole body from head to feet, are followed depending on the subject's functional capabilities. In an effort to maintain the alignment of different body's segments (head, torso, pelvis, lower limbs) objective, young subjects have the capacity to regulate their spino-pelvic alignment by fine-tuning the curvature of their spine and adjusting the orientation of their pelvis. In comparison, it has been demonstrated that older subjects recruit preferably mechanisms of compensation at the pelvis and lower limbs levels [5].

Evaluation of the posture has been made in the past by studying the spine and pelvis on sagittal X-rays [6-9]. To our knowledge, only two studies reported the alignment of the head with the rest of the body, stating that the inclination of the head compared to the pelvis could be a good indication of the postural trouble $[10,11]$ while others only focused on the alignment of $\mathrm{C} 7$ with the rest of the spine and pelvis $[12,13]$. Previous clinical studies included the lower limbs, massively in 2D (not relevant for torsion values for example) [14]. However reference values, in 2D and 3D, of the complete global alignment of the normal young adult from a whole body (head to feet) exam are not yet available.

The aim of the current study was to study the postural alignment of young asymptomatic subject including head, spine, pelvis and lower limbs, in 2D and 3D. Possible invariant parameters of the young adults' posture were investigated.

\section{Materials and methods}

\section{Volunteers and data selection}

69 volunteers (32 male and 37 female) were retrospectively included in the study: bi-planar X-rays radiographies were obtained between February 2007 and July 2014 after approval by the Ethics Committee (Comite de Protection des Personnes CPP $\mathrm{N}^{\circ}$ 06036) and written informed consent. Bi-planar X-rays were obtained with the EOS system, a low-dose system allowing acquiring simultaneously radiographies in the sagittal and coronal planes of the patient (with two sources at $90^{\circ}$ ), from head to feet [15]. Inclusion of the EOS radiographies in the study required total visibility of the lower limbs bones and vertebrae on both views. Among exclusion criteria were previous musculo-skeletal surgery, previous surgery or pathology concerning the visual and/or the hearing system(s). Patients

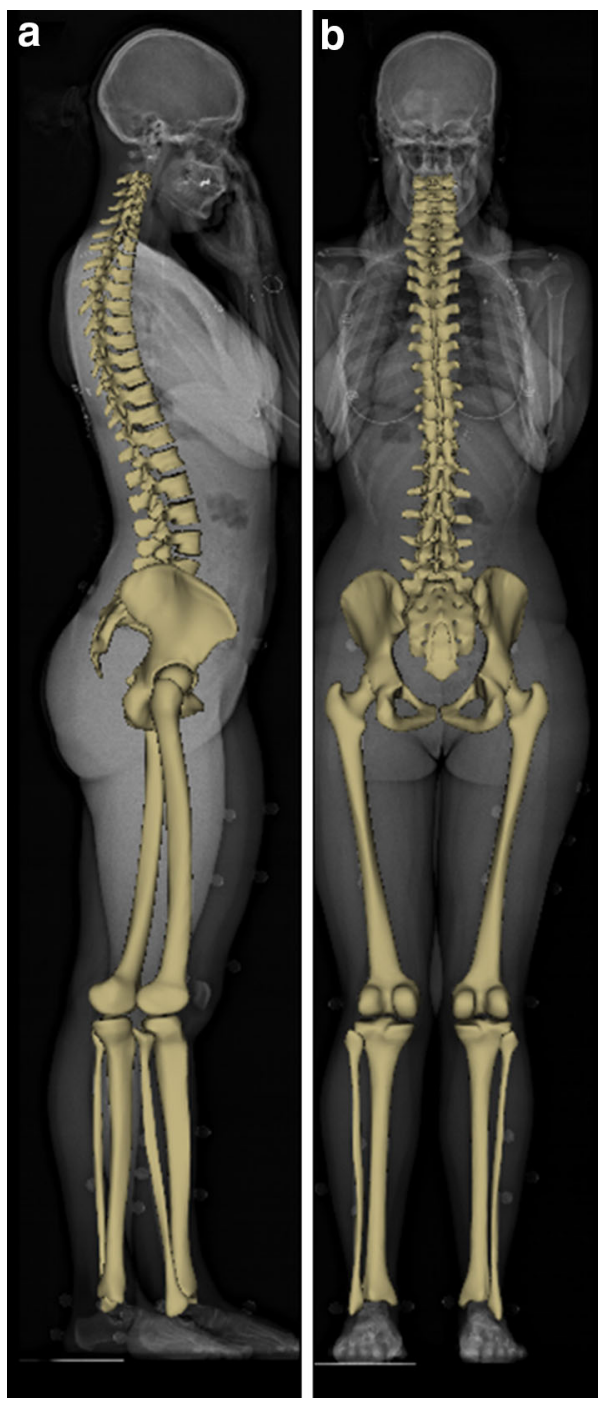

Fig. 1 Bi-planar radiographies with 3D model of the spine (C3 to L5), pelvis and lower limbs a sagittal view, b coronal view

were asked to stand up in the standardized free standing position, adapted from Faro et al. [16], with the hands resting on the mandibles (SRS modified free standing position) and with shifted feet positioned as described by Chaïbi et al. [17] (Fig. 1).

\section{Imaging data processing}

From bi-planar X-rays, a 3D patient-specific model including the spine [from $\mathrm{C} 3$ to L5, with addition of the most superior point of dentiform apophyse of C2 (OD)], the pelvis, and the lower limbs; was obtained using validated reconstructions techniques [17-20] (Fig. 2a). In addition, as described by Steffen et al. [10], when visible, two stereo-corresponding points localizing the acoustic meati were digitized to each reconstruction to compute their center (CAM) (Fig. 2b). 

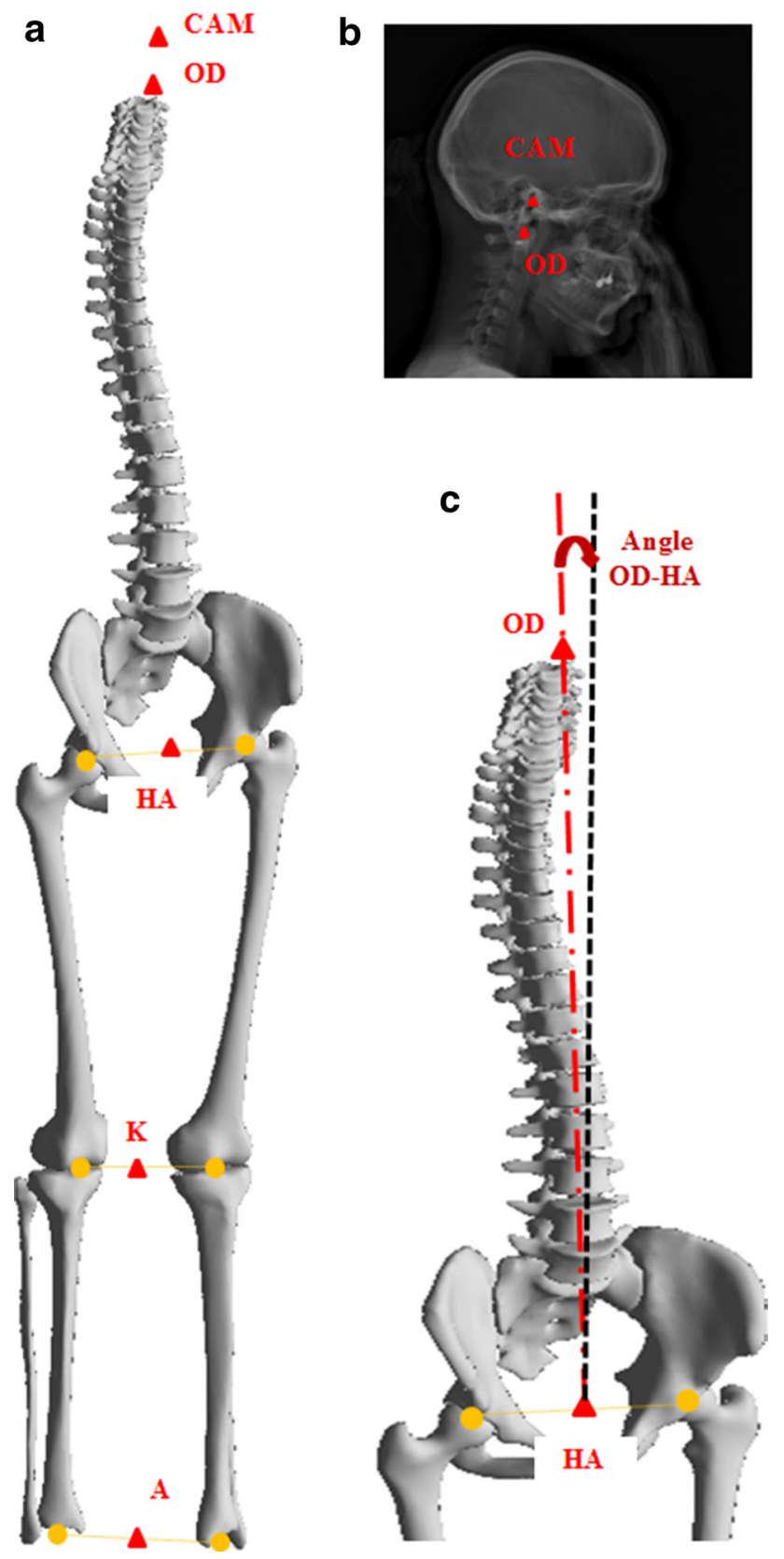

Fig. 2 a 3D model of the spine (C3 to L5), pelvis and lower limbs: identification of the center of the acoustic meati (CAM), the most superior point of dentiform apophyse of C2 (OD), the centers of T1 and T9 vertebral bodies (T1 and T9), the center of the sacral plate (S1), the center of the bi-coxofemoral axis (HA), the middle of both knees points $(\mathrm{K})$, and the middle of both ankles (A). b Detailed identification of CAM and OD points on the sagittal radiography. c Example of OD-HA parameter: angle with the vertical of the line joining the points OD and HA

\section{Studied parameters}

All the parameters were calculated in the anatomo-gravital frame, which is the patient frame: the frontal plane is the vertical plane going through both acetabulum centers',
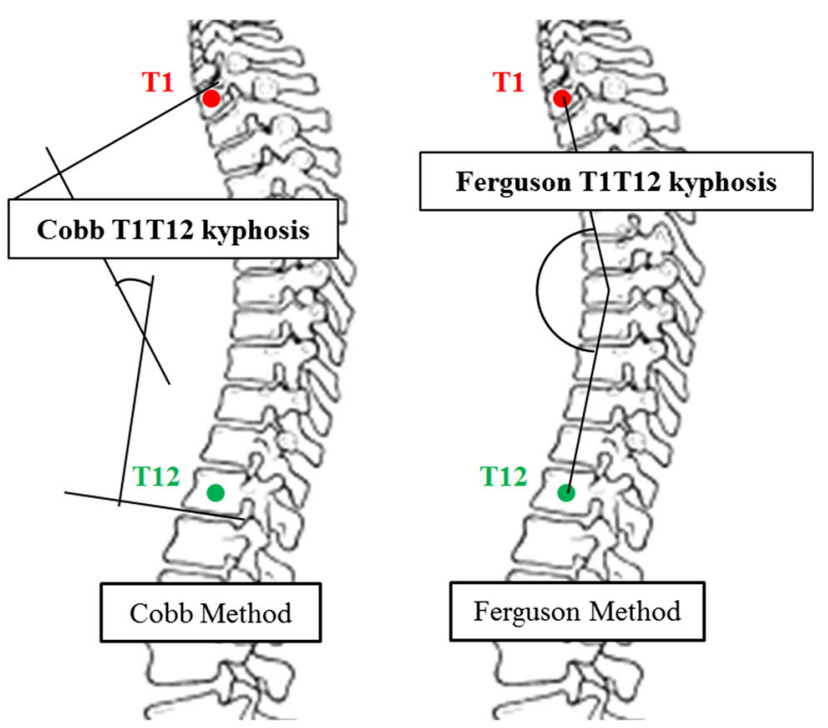

Fig. 3 Differences between Cobb method and Ferguson method to calculate spinal curvatures (example of kyphosis T1T12)

transversal and sagittal planes are orthogonal to the frontal plane. The origin of the frame is the center of the bi-coxofemoral segment (point named HA). Parameters' definitions are detailed in Tables 2 and 3.

Pelvic (pelvic incidence, pelvic tilt and sacral slope) and lower limbs parameters were calculated from 3D reconstruction. Spinal curvatures (cervical lordosis, thoracic kyphosis and lumbar lordosis) were calculated using both Cobb and Ferguson methods (Fig. 3).

Angles of the vertical with specific lines going through various landmarks (Fig. 2) were also calculated.

Two global alignment lines were defined, searching for the most invariant one among subjects (defined as the one with the smallest standard deviation). The first line was defined as the line that best fits (in the least square sense), the following anatomical landmarks: middle of the centers of acoustic meati (CAM), the most superior point of dentiform apophyse of C2 (OD), all the vertebral bodies' center from C3 to L5, center of the sacral plate (S1) and middle of the centers of each acetabulum (HA). The second line was defined similarly without including the CAM point in the landmarks considered.

As proposed by Steffen et al. [10], offsets of the following points were calculated CAM, T1, T4, T9, L3, and S1. We also considered the most superior point of dentiform apophyse of C2 (OD), the center of the knees (K) as the middle points of right and left middle point between condyles' centers and tibial plates' centers. The center of ankles (A) was also considered as the middle point of right and left centers of bimalleolar axis. Figure 2a presents all the points considered for offsets analysis. The offsets were calculated, in $3 \mathrm{D}$, and in both directions of the transversal 
plane (postero-anterior and medio-lateral), as the distance between these points and the vertical going through HA.

The reliability of each point was already described elsewhere except for the OD location [19]. For this parameter, two operators digitized the points two times for 12 patients on two distinct set of radiographies for each (48 repetitions per operator): $95 \%$ confidence interval was respectively of $2.0 \mathrm{~mm}$ for $X$, antero-posterior direction; of $1.2 \mathrm{~mm}$ for $Y$, medio-lateral direction; and of $2.2 \mathrm{~mm}$ for $Z$, superior direction.

\section{Statistical analysis}

A paired-sample $t$ test was run on lower limbs' parameters to find if there was any statistical difference between right and left sides [21].

A Lilliefors normality test [22] was run on all parameters. Correlations were searched for using pairwise Spearman correlations (significance level was set at 0.05).

\section{Results}

\section{Description of the sample}

Mean age was 26.3 years old [standard deviation (SD): 4.7 years old] (Table 1 ). The acoustic meati were not visible on 8 EOS exams out of the 69. Over all parameters used to study correlations, 13 were found to not be drawn from a normal distribution (Table 2). As these parameters' distributions were found, by the operators, to be close to a bell-shape, means and SD were reported for all parameters (Tables 2, 3).

In average, pelvic incidence, pelvic tilt, and sacral slope

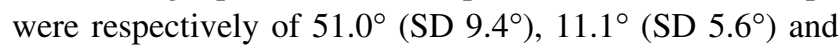
$40.5^{\circ}\left(\mathrm{SD} 8.7^{\circ}\right)$. As for the spine curvatures, the 3D T1T12 thoracic kyphosis was in average of $26.9^{\circ}$ (SD 7.2 $2^{\circ}$ ) versus $30.5^{\circ}\left(\mathrm{SD} 7.5^{\circ}\right)$ for the L1S1 lumbar lordosis.

\section{Analysis of the least variant parameter(s)}

The inclinations, with the vertical, of the line joining CAM to HA and of the line joining OD to HA had the lowest

Table 1 Demographic data of the volunteers who participated in the study

\begin{tabular}{lcc}
\hline & Age (years) $)^{\mathrm{a}}$ & BMI $\left(\mathrm{kg} / \mathrm{m}^{2}\right)^{\mathrm{a}}$ \\
\hline Mean & 26.3 & 22.4 \\
$1 \times$ standard deviation & 4.7 & 3.1 \\
Min & 20.1 & 16.6 \\
Max & 39.7 & 33.2
\end{tabular}

${ }^{a}$ Means that the parameter was not found to be drawn from a normal distribution variation with a SD respectively of $1.7^{\circ}$ and of $1.6^{\circ}$ and were the closest to the vertical: mean inclination of $2.9^{\circ}$ for both. In comparison, means (SD) of C7-HA, T1-HA and T9-HA were respectively of $4.3^{\circ}\left(1.9^{\circ}\right) ; 5.5^{\circ}\left(2.0^{\circ}\right)$ and $10.6^{\circ}\left(2.8^{\circ}\right)$.

As for the lines that could possibly represent the global inclination of the spine, the less variable inclinations between subjects were when using the two following combinations of points for the calculation of the leastsquared line: (1) CAM, OD, centers of C3 to L5 vertebral bodies (line called Incl_1), and S1; (2) OD, centers of C3 to L5 vertebral bodies, and S1 (line called Incl_2). Values are reported in Table 3 .

When considering the offsets between HA and different plumblines (Fig. 4) dropped from the specific anatomical landmarks (CAM, OD, T1, T4, T9, L3, S1, K, A), the average distances ranged from 70.3 to $10.7 \mathrm{~mm}$ posterior to $\mathrm{HA}\left(\mathrm{SD}_{\max }=24.1 \mathrm{~mm}\right)$ and from 5.1 medial to $2.3 \mathrm{~mm}$ lateral to $\mathrm{HA}\left(\mathrm{SD}_{\max }=14.2 \mathrm{~mm}\right)$. The distance in the transverse plane ranged from 17.9 to $71.5 \mathrm{~mm}$ $\left(\mathrm{SD}_{\max }=21.2 \mathrm{~mm}\right)$. The center of the sacral plate $\mathrm{S} 1$, versus HA, presented the lowest variable offset across subjects, in the transverse plane (mean $20.9 \mathrm{~mm}$; SD $9.4 \mathrm{~mm}$ ). On average, the knee's center and ankles' center were posterior to $\mathrm{HA}$ in average less than $6 \mathrm{~cm}$ $(\mathrm{SD}<2 \mathrm{~cm})$ and were lateral to $\mathrm{HA}$ in average less than $1 \mathrm{~cm}(\mathrm{SD}<1.5 \mathrm{~cm})$.

\section{Statistical analysis}

As, the paired-sample $t$ tests revealed that specific parameters (Table 2) presented no statistical differences between both sides, the value kept for analysis was the mean of the right and left values.

Cobb versus Ferguson relationship for spinal curvatures was: Cobb $_{\mathrm{sag}}=1.90 \times$ Ferguson $_{\mathrm{sag}}-2.34 \quad\left(R^{2}=0.96\right.$, $p$ value $<0.05)$. The pairwise correlations found to be significant ( $p$ value $<0.05$ ) are the following ones: L1S1 lordosis with sacral slope $\left(R^{2}=0.87\right)$, with pelvic incidence $\left(R^{2}=0.62\right)$, and with thoracic kyphosis (T4T12: $R^{2}=0.48$; T1T12: $R^{2}=0.36$ ); overhang of $\mathrm{S} 1$ with pelvic tilt $\left(R^{2}=0.97\right)$. No significant correlation was found between spinal and lower limbs parameters.

\section{Discussion}

Erected posture of 69 young asymptomatic adults was described from head to feet in 3D and 2D. If, compensatory mechanisms of the pelvis and lower limbs have been documented in the literature, few have been reported for the cervical level: studying the skeleton postural alignment from head to feet allows for a complete view of the 
Table 2 Reference values for pelvic and lower limbs parameters: Mean (SD)

\begin{tabular}{|c|c|c|c|}
\hline Abbreviation & Name & Mean $(1 \times \mathrm{SD})$ & \\
\hline PI & Pelvic incidence $\left({ }^{\circ}\right)$ & $51.0(9.4)$ & \\
\hline SS & Sacral slope $\left(^{\circ}\right)$ & $40.5(8.7)$ & \\
\hline PT & Pelvic tilt $\left(^{\circ}\right)$ & $11.1(5.6)$ & \\
\hline $\mathrm{S} 1_{\mathrm{ov}}$ & Overhang of S1 (postero-anterior distance between S1 and HA) (mm) & $-19.6(10.2)$ & \\
\hline SVA & $\begin{array}{l}\text { Sagittal vertical axis (postero-anterior distance between } \mathrm{C} 7 \text { and }{ }^{\text {post-sup }} \mathrm{S} 1 \text { ) } \\
(\mathrm{mm})\end{array}$ & $-8.9(21.6)$ & \\
\hline TPA & $\mathrm{T} 1$ pelvic angle (angle between line $\mathrm{T} 1$ to $\mathrm{HA}$ and line $\mathrm{S} 1$ to $\mathrm{HA}$ ) $\left(^{\circ}\right.$ ) & $5.3(5.7)$ & \\
\hline $\mathrm{PR}^{\mathrm{a}}$ & $\begin{array}{l}\text { Pelvic rotation (angle between the frontal plane of the acquisition system and } \\
\text { the frontal plane of the anatomo-gravital frame) }\left(^{\circ}\right)\end{array}$ & $3.2(2.5)$ & \\
\hline $\mathrm{PO}$ & $\begin{array}{l}\text { Pelvic obliquity (angle between the bi-coxofemoral axis and its projection on } \\
\text { the horizontal plane) }\left({ }^{\circ}\right)\end{array}$ & $-0.3(2.5)$ & \\
\hline${ }^{\wedge} \operatorname{Cov}_{\mathrm{ext}}$ & External coverture angle $\left(^{\circ}\right)$ & R: $29.6(5.6)$ & L: $29.8(5.3)$ \\
\hline${ }^{\wedge} \mathrm{Cov} \%$ & Acetabular coverage $(\%)[23]$ & R: $46.5(3.5)$ & L: $46.0(3.5)$ \\
\hline${ }^{\wedge}$ Incl $_{\text {acetab }}$ & Acetabular inclination $\left({ }^{\circ}\right)$ & R: $34.1(3.4)$ & L: 33.8 (2.9) \\
\hline$\wedge \mathrm{Abd}_{\text {acetab }}$ & Acetabular abduction $\left(^{\circ}\right)$ & R: $57.4(4.4)$ & L: $57.0(3.9)$ \\
\hline Antev $_{\text {acetab }}$ & Acetabular anteversion $\left({ }^{\circ}\right)$ & R: $15.5(3.5)$ & L: 16.7 (3.6) \\
\hline $\mathrm{HKS}^{\mathrm{a}}$ & Hip-knee centers-femoral shaft angle $\left(^{\circ}\right)$ & $\mathrm{R}: 5.5(1.3)$ & L: $5.2(1.5)$ \\
\hline$\wedge \mathrm{TMA}$ & Tibial mechanical angle $\left(^{\circ}\right)$ & R: $87.2(2.2)$ & L: $87.4(2.0)$ \\
\hline$\wedge$ FMA & Femoral mechanical angle $\left(^{\circ}\right)$ & R: 92.9 (1.7) & L: $92.6(2.2)$ \\
\hline$\wedge$ FT & Femoral torsion $\left(^{\circ}\right)$ & R: $12.9(9.6)$ & L: 13.8 (10.8) \\
\hline ^ $\mathrm{TT}$ & Tibial torsion $\left(^{\circ}\right)$ & R: $37.1(6.0)$ & L: $35.9(6.7)$ \\
\hline$L_{\mathrm{F}}$ & Femoral length (mm) & R: 426.4 (24.6) & L: $427.5(24.4)$ \\
\hline${ }^{\wedge} L_{\mathrm{T}}$ & Tibial length (mm) & R: 368.0 (21.9) & L: $368.3(22.0)$ \\
\hline$L_{\text {Tot }}$ & Lower limb length (mm) & R: 798.9 (45.6) & L: $800.2(45.9)$ \\
\hline${ }^{\wedge} \mathrm{FTR}^{\mathrm{a}}$ & Femoro-tibial rotation $\left({ }^{\circ}\right)$ & R: 6.3 (3.9) & L: $6.6(5.7)$ \\
\hline${ }^{\wedge} \mathrm{FTMA}^{\mathrm{a}}$ & Femoro-tibial mechanical angle $\left(^{\circ}\right)$ (also called HKA) & R: $174.7(3.1)$ & L: $174.9(2.6)$ \\
\hline$\wedge$ FNSA & Femoral neck shaft angle $\left(^{\circ}\right)$ & R: $128.3(4.4)$ & L: $128.0(3.7)$ \\
\hline$\wedge \mathrm{FO}$ & $\begin{array}{l}\text { Femoral offset (3D distance between the center of femoral head and the } \\
\text { proximal diaphyseal axis) (mm) }\end{array}$ & R: $40.1(5.5)$ & $\mathrm{L}: 40.6(4.2)$ \\
\hline
\end{tabular}

S1 centre of sacral plate, $H A$ middle of the centers of each acetabulum, $C 7$ center of vertebral body of C7, $T 1$ center of vertebral body of T1, ${ }^{\text {post }}$ ${ }^{s u p} S 1$ most posterior point of the superior plate of $\mathrm{S} 1, R(L)$ right (left) side

${ }^{\wedge}$ Means that for the correlation study, the values were averaged between right and left sides (as no statistical differences were reported by the paired $t$ test ran)

${ }^{a}$ Means that the parameter was not found to be drawn from a normal distribution

possible compensatory mechanisms. For example, Sugrue et al. is one study of the few to include points at the head level (cranial center of mass of the head and C2) [11]. Overall, our findings match the ones previously reported in the literature, with new information regarding the global postural alignment from head to feet, and in particular the position of the head relative to the pelvis.

\section{Spinal and pelvic parameters}

Agreement with the literature was found for the hip joints' parameters $\left(\mathrm{Cov} \%, \mathrm{Abd}_{\mathrm{acetab}}, \mathrm{Antev}_{\mathrm{acetab}}\right)[14,23]$, and for spinal and pelvic parameters [6-9, 17, 24, 25], particularly with the studies conducted by Vialle et al. [8] and by Schwab et al. [25].
The correlations found between spinal curvatures and pelvic parameters are similar to the correlations reported in the literature [6-9, 24]. In particular, Vialle et al. found a strong correlation between the L1L5 lordosis and the sacral slope $\left(R^{2}=0.76\right)$ and a strong correlation between the L1L5 lordosis and the pelvic incidence $\left(R^{2}=0.68\right)$ [8]. These correlations highlight the influence of the morphology of the pelvis on the lumbar spinal curvature. As for Cobb versus Ferguson values, the relationship found is consistent with the literature [26].

\section{Lower limbs parameters}

For the lower limbs geometrical parameters (HKS, ^ TMA, ${ }^{\wedge} \mathrm{FMA},{ }^{\wedge} \mathrm{FT}$, ${ }^{\wedge} \mathrm{TT}, L_{\mathrm{F}},{ }^{\wedge} L_{\mathrm{T}}, L_{\mathrm{Tot}},{ }^{\wedge} \mathrm{FTR},{ }^{\wedge} \mathrm{FTMA},{ }^{\wedge} \mathrm{FNSA}$, 
Table 3 Reference values for spinal parameters and inclinations in 3D/sagittal plane/frontal plane: mean (SD)

\begin{tabular}{|c|c|c|c|c|}
\hline Abbreviation & Description of the line & $3 \mathrm{D}$ & Frontal plane & Sagittal plane \\
\hline $\mathrm{L}_{\mathrm{C} 3-\mathrm{C} 7}^{\mathrm{a}}$ & C3-C7 lordosis $\left(^{\circ}\right) \# 3.7(0.1)$ & $8.6(4.5)$ & $2.6(5.2)$ & $-0.9(8.5)$ \\
\hline $\mathrm{K}_{\mathrm{T} 1-\mathrm{T} 12}^{\mathrm{a}}$ & T1-T12 kyphosis $\left(^{\circ}\right) \# 49.0$ (13.0) & $26.9(7.2)$ & $-1.1(5.4)$ & $26.7(7.3)$ \\
\hline $\mathrm{K}_{\mathrm{T} 4-\mathrm{T} 12}^{\mathrm{a}}$ & $\mathrm{T} 4-\mathrm{T} 12$ lordosis $\left(^{\circ}\right) \# 35.1$ (11.5) & $19.2(6.1)$ & $1.5(5.4)$ & $18.6(6.6)$ \\
\hline $\mathrm{L}_{\mathrm{L} 1-\mathrm{L} 5}^{\mathrm{a}}$ & L1-L5 lordosis $\left(^{\circ}\right) \#-46.4$ (11.9) & $21.8(5.9)$ & $-3.5(6.6)$ & $-20.7(5.6)$ \\
\hline $\mathrm{L}_{\mathrm{L} 1-\mathrm{S} 1}^{\mathrm{a}}$ & $\mathrm{L} 1-\mathrm{S} 1$ lordosis $\left(^{\circ}\right) \#-57.6(12.8)$ & $30.5(7.5)$ & $0.4(10.1)$ & $-30.1(7.6)$ \\
\hline $\mathrm{A}_{\text {Pelvis-Fem }}$ & $\begin{array}{l}\text { Angle between the bi-coxofemoral axis } \\
\text { and the bi-condylar axis }\left(^{\circ}\right)\end{array}$ & $\begin{array}{l}\text { R: } 16.4(8.4) \\
\text { L: } 15.4(7.7)\end{array}$ & $\begin{array}{l}\text { R: } 38.3(175.0) \\
\text { L: } 74.2(162.8)\end{array}$ & - \\
\hline Incl_1 & $\begin{array}{l}\text { Global Inclination: Angle between the } \\
\text { vertical and the line that best fits: CAM, } \\
\text { OD, all the vertebral body' centers from } \\
\text { C } 3 \text { to L5, and } \mathrm{S} 1\left(^{\circ}\right)^{\text {b }}\end{array}$ & $3.1(1.9)$ & $-0.5(1.1)$ & $-2.3(2.6)$ \\
\hline Incl_2 & $\begin{array}{l}\text { Global Inclination: Angle between the } \\
\text { vertical and the line that best fits: OD, } \\
\text { all the vertebral body' centers from C3 } \\
\text { to L5, and } \mathrm{S} 1\left(^{\circ}\right)^{\mathrm{b}}\end{array}$ & $3.5(2.1)$ & $-0.5(1.3)$ & $-2.8(2.7)$ \\
\hline CAM-HA ${ }^{\mathrm{a}}$ & $\begin{array}{l}\text { Angle between the vertical and the line } \\
\text { that connects CAM to HA }\left(^{\circ}\right)\end{array}$ & $2.9(1.7)$ & $-0.3(1.0)$ & $-2.4(2.1)$ \\
\hline OD-HA & $\begin{array}{l}\text { Angle between the vertical and the line } \\
\text { that connects OD to HA }\left(^{\circ}\right)\end{array}$ & $2.9(1.6)$ & $-0.4(1.2)$ & $-2.3(2.0)$ \\
\hline C7-HA & $\begin{array}{l}\text { Angle between the vertical and the line } \\
\text { that connects } \mathrm{C} 7 \text { to } \mathrm{HA}\left({ }^{\circ}\right)\end{array}$ & $4.3(1.9)$ & $-0.2(1.4)$ & $-4.0(2.1)$ \\
\hline CAM-C7 & $\begin{array}{l}\text { Angle between the vertical and the line } \\
\text { that connects CAM to } \mathrm{C} 7\left({ }^{\circ}\right)\end{array}$ & $6.8(4.2)$ & $-1.0(2.7)$ & $4.1(6.3)$ \\
\hline $\mathrm{OD}-\mathrm{C}^{\mathrm{a}}$ & $\begin{array}{l}\text { Angle between the vertical and the line } \\
\text { that connects } \mathrm{OD} \text { to } \mathrm{C} 7\left(^{\circ}\right)\end{array}$ & $8.0(4.5)$ & $-1.7(3.4)$ & $5.6(6.3)$ \\
\hline T1-HA & $\begin{array}{l}\text { Angle between the vertical and the line } \\
\text { that connects } \mathrm{T} 1 \text { to } \mathrm{HA}\left({ }^{\circ}\right)\end{array}$ & $5.5(2.0)$ & $-0.1(1.4)$ & $-5.3(2.1)$ \\
\hline T9-HA & $\begin{array}{l}\text { Angle between the vertical and the line } \\
\text { that connects T9 to HA. }\left(^{\circ}\right)\end{array}$ & $10.6(2.8)$ & $0.1(1.7)$ & $-10.4(2.8)$ \\
\hline $\mathrm{T} 1-\mathrm{S} 1$ & $\begin{array}{l}\text { Angle between the vertical and the line } \\
\text { that connects } \mathrm{T} 1 \text { to } \mathrm{S} 1\left(^{\circ}\right)\end{array}$ & $4.5(2.2)$ & $-0.2(1.4)$ & $-4.1(2.7)$ \\
\hline \multirow[t]{2}{*}{$\mathrm{FI}^{\mathrm{a}}$} & \multirow{2}{*}{$\begin{array}{l}\text { Femoral inclination (angle of the femoral } \\
\text { mechanical axis with the vertical) }\left(^{\circ}\right)\end{array}$} & R: 6.3 (3.3) & $\mathrm{R}:-0.7$ (1.9) & R: 5.7 (3.8) \\
\hline & & L: 8.3 (3.5) & L: 0.6 (1.9) & L: 8.0 (3.6) \\
\hline \multirow[t]{2}{*}{ TI } & \multirow{2}{*}{$\begin{array}{l}\text { Tibial inclination (angle of the tibial } \\
\text { mechanical axis with the vertical) }\left({ }^{\circ}\right)\end{array}$} & R: 4.5 (2.0) & $\mathrm{R}:-2.5(2.2)$ & R: 1.4 (3.4) \\
\hline & & L: 5.0 (2.7) & L: $2.3(2.0)$ & L: 3.6 (3.3) \\
\hline
\end{tabular}

For the spinal curvatures, the values in the second column following the \# symbol are the values computed with the Cobb method. $R(L)$ right (left) side

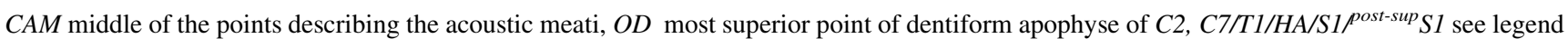
of Table 2, T4 (T9) center of vetebral body of T4 (T9)

${ }^{\mathrm{a}}$ means the parameter that was not found to be drawn from a normal distribution and ${ }^{\mathrm{b}}$ means in the least square sense

FO), the values found match values reported in studies using computer tomography in the supine position and in studies evaluating lower limbs' geometry on 3D model build from bi-planar radiographies [17, 27].

\section{Global alignment parameters}

The inclination of the line joining CAM and HA and the line joining OD and HA are the less variable among subjects (respectively $\mathrm{SD}=1.7^{\circ}$ and $\mathrm{SD}=1.6^{\circ}$ ). The line with the OD point is less variable between subjects and more robust when it comes to digitizing the point on the radiographies.

Few studies reported values for inclinations: values similar to those reported in the literature were found for inclinations of the line going through T9 and HA (T9-HA); of the line going through T1 and S1 (T1-S1); of the line going through T1 and HA (T1-HA) and of the least square line going through $\mathrm{OD}$, all the vertebral bodies from $\mathrm{C} 3$ to L5 and S1 (Incl_2) [7, 28]. Another alignment parameter is the T1 pelvic alignment (TPA) reflecting the inclination of the trunk and pelvic retroversion (accounting for both SVA 
Fig. 4 Offsets from the vertical going through the center of the bi-coxofemoral axis (HA) $($ mean $\pm 1 \times \mathrm{SD})$
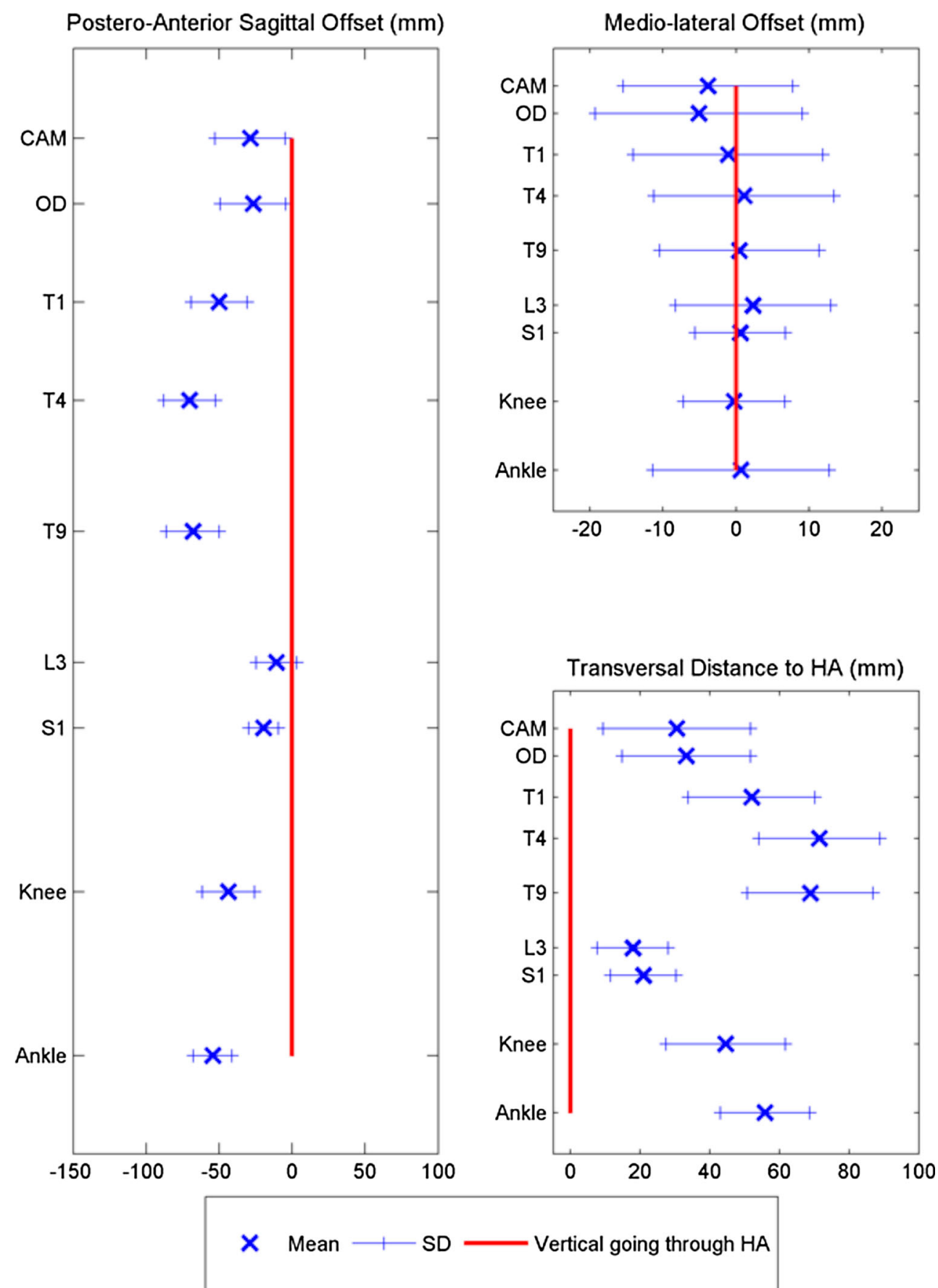

and PT). Ryan et al. reported a value of TPA less than $15.9^{\circ}$ for patients with adult spinal deformities well aligned [29], proposing a surgical target of $10^{\circ}$ for TPA. For young asymptomatic adults (well aligned), mean TPA is $5.3^{\circ}$ $\left(\mathrm{SD}=5.7^{\circ}\right)$.which means that $66 \%$ of the population ranges between $-0.4^{\circ}$ and $11.0^{\circ}$. Some have subnormal values, between mean $-2 \times \mathrm{SD}$ and mean $-1 \times \mathrm{SD}$ (respectively between mean $+1 \times \mathrm{SD}$ and mean + $2 \times \mathrm{SD}$ ) which can reach $-6.1^{\circ}$ (respectively $16.7^{\circ}$ ). This shows that the target set by Ryan et al. [29] could be adjusted to identify abnormalities.
For the global inclinations, the least squared line going through the points CAM, OD, centers of vertebral bodies from C3 to L5 and S1 (Incl_1 in Table 3) presented an inclination of $3.1^{\circ}$ in average (SD $1.9^{\circ}$ ) versus $3.5^{\circ}$ in average $\left(\mathrm{SD} 2.1^{\circ}\right)$ for the second least-squared line (Incl_2), going through OD, centers of vertebral bodies from C3 to L5 and S1. The line used in Incl_1 is more vertical and less variable between subjects but the weaker digitization of CAM makes it less robust.

The $\mathrm{C} 7$ point can be useful when CAM and/or OD are not visible on the radiographies. The $\mathrm{C} 7-\mathrm{HA}$ inclination is 
slightly greater than CAM-HA $\left(4.3^{\circ}\right.$ versus $\left.2.9^{\circ}\right)$ and only very slightly more variable (SD: $1.9^{\circ}$ versus $1.7^{\circ}$ ). It will be interesting to investigate whether this parameter is more variable in older subjects.

The CAM-HA or OD-HA parameter will be useful to assess the global alignment taking into account the cervical part of the spine contrary to the SVA and C7-HA parameter. Depending on the use and interpretation, studies could use CAM, OD or $\mathrm{C} 7$ points to characterize global alignment with CAM-HA, OD-HA, SVA and C7-HA that appear as complementary parameters. In addition, it will be interesting to further investigate changes for pathological and aging population, in the newly described parameters (CAM-HA and OD-HA) compared to SVA and C7-HA.

CAM and OD points were chosen to account for the head position. Previous studies have focused on other specific points to quantify alignment of the head with the spine and pelvis: such as the sella turcica [13], McGregor line [13], or cranial center of mass (as the midpoint of the nasion-inion line) [11]. Commonly to the current study, all considered points supposed to be close to the true center of mass of the head to quantify its alignment compared to the pelvis. However, in analyzing radiographs, a reliable and accurate but also easy-to-implement method is needed to identify points of interest (particularly when working in a clinical environment). That is why in this study, only points directly identifiable on the 3D model of the spine were considered: for the head, this included only the points CAM and OD. It can be noted that all these studies including this one, concluded on the importance of the position of the head above the pelvis in the global postural alignment $[11,13]$.

\section{Offsets}

Variability between subjects (SD) was comparable between the angles, measured in the sagittal planes: CAM-HA $\left(\mathrm{SD}=2.1^{\circ}\right), \quad \mathrm{OD}-\mathrm{HA} \quad\left(\mathrm{SD}=2.0^{\circ}\right) \quad$ and $\quad \mathrm{C} 7-\mathrm{HA}$ $\left(\mathrm{SD}=2.1^{\circ}\right)$. Inter-subject variability was greater for the angle corresponding to SVA: angle with the vertical of the line joining through $\mathrm{C} 7$ and ${ }^{\text {post-sup }} \mathrm{S} 1\left(\mathrm{SD}=2.8^{\circ}\right)$. This suggests that the use of the point ${ }^{\text {post-sup }} \mathrm{S} 1$ accounts for the inclination of the pelvis as well in this angle, when compared to the angle C7-HA using the point HA. Comparison of the angles CAM-HA, OD-HA and C7-HA highlighted that, for asymptomatic volunteers, these data variability are similar. It would be particularly interesting to assess changes occurring during aging and/or pathological conditions. Studies' reported offsets used the gravity line as the reference line $[10,25,30]$, using a forceplate simultaneously to the X-ray acquisition. Experimental setup did not provided forceplate data, thus we decided to use the vertical going through the center of the bi-coxofemoral axis (HA) as the reference line and not the heels as done in
Schwab et al. [25] as, here, the feet's positions were not found to be consistent enough between all subjects to be used as a reference line. Despite these differences, our values are of the same order of magnitude as the literature's $[10,25,30]$. In addition, it can be noted that offsets of both knees' and ankles' centers were found to be relatively close to HA in the transverse plane (less than $6 \mathrm{~cm}$ ): this provides a baseline for comparison with older subjects.

\section{Limitations}

One limitation is the non-uniform age distribution: more subjects between 30 and 40 years old might highlight some correlations between all the parameters that were hidden here. Another limitation resides in the position of the subject in the X-ray cabin. Particularly, the position of the hands on the mandibles might have affected the volunteer's posture by shifting backwards the upper body to make room for the arms flexed. In addition, the shift between the feet must be controlled to be consistent between subjects. Monitoring more precisely the patient's position would lead to more reliable results characteristics of the true subject's erected posture.

\section{Conclusion}

In conclusion, a description of the postural alignment in 3D, and in sagittal and frontal planes of the young healthy adult has been reported. As hypothesized, the head is, for each subject, placed above the pelvis (line CAM-HA little variable). In this control group, the spine is globally vertical as the parameter Incl_1 and Incl_2 are close to $0^{\circ}$. We described the postural alignment and the geometry of the following segments: spine, pelvis, lower limbs. This study on young healthy adults (18-40 years old) would allow future comparisons for older population.

Acknowledgments Authors thank the ParisTech BiomecAM chair program on subject-specific musculoskeletal modeling, and in particular COVEA and Société Générale.

\section{Compliance with ethical standards}

Conflict of interest Wafa Skalli is the coinventor of the EOS system without direct/personal financial benefit. Her institution received financial support from the ParisTech Chair Program for research on musculoskeletal research.

\section{References}

1. Dubousset J (1994) Three-dimensional analysis of the scoliotic deformity. In: Weinstein SL (ed) Pediatric spine: principles and practices. Raven Press ltd, NY, pp 479-496 
2. Vital JM, Senegas J (1986) Anatomical bases of the study of the constraints to which the cervical spine is subject in the sagittal plane A study of the center of gravity of the head. Surg Radiol Anat 8:169-173

3. Barrey C, Roussouly P, Le Huec J-C et al (2013) Compensatory mechanisms contributing to keep the sagittal balance of the spine. Eur Spine J 22:S834-S841. doi:10.1007/s00586-013-3030-z

4. Roudsari BS, Ebel BE, Corso PS et al (2005) The acute medical care costs of fall-related injuries among the US older adults. Injury 36:1316-1322. doi:10.1016/j.injury.2005.05.024

5. Diebo B, Ferrero E, Lafage R et al (2015) Recruitment of compensatory mechanisms in sagittal spinal malalignment is age dependent: an EOS analysis of Spino-pelvic mismatch. Spine (Phila Pa 1976). doi:10.1097/BRS.0000000000000844

6. Legaye J, Duval-Beaupère G, Hecquet J, Marty C (1998) Pelvic incidence: a fundamental pelvic parameter for three-dimensional regulation of spinal sagittal curves. Eur Spine J 7:99-103

7. Rajnics P, Pomero V, Templier A et al (2001) Computer-assisted assessment of spinal sagittal plane radiographs. J Spinal Disord 14:135-142. doi:10.1097/00002517-200104000-00008

8. Vialle R, Levassor N, Rillardon L et al (2005) Radiographic analysis of the sagittal alignment and balance of the spine in asymptomatic subjects. J Bone Joint Surg Am 87:260-267. doi:10.2106/JBJS.D.02043

9. Boulay C, Tardieu C, Hecquet J et al (2006) Sagittal alignment of spine and pelvis regulated by pelvic incidence: standard values and prediction of lordosis. Eur Spine J 15:415-422. doi:10.1007/ s00586-005-0984-5

10. Steffen J, Obeid I, Aurouer N et al (2010) 3D postural balance with regard to gravity line: an evaluation in the transversal plane on 93 patients and 23 asymptomatic volunteers. Eur Spine J 19:760-767

11. Sugrue PA, McClendon J, Smith TR et al (2013) Redefining global spinal balance: normative values of cranial center of mass from a prospective cohort of asymptomatic individuals. Spine (Phila $\mathrm{Pa}$ 1976) 38:484-489. doi:10.1097/BRS.0b013e318273a1c0

12. Kim YB, Kim YJ, Ahn YJ et al (2014) A comparative analysis of sagittal spinopelvic alignment between young and old men without localized disc degeneration. Eur Spine J 23:1400-1406. doi:10.1007/s00586-014-3236-8

13. Le Huec JC, Demezon H, Aunoble S (2014) Sagittal parameters of global cervical balance using EOS imaging: normative values from a prospective cohort of asymptomatic volunteers. Eur Spine J 24:63-71. doi:10.1007/s00586-014-3632-0

14. Seber S, Hazer B, Köse N et al (2000) Rotational profile of the lower extremity and foot progression angle: computerized tomographic examination of 50 male adults. Arch Orthop Trauma Surg 120:255-258

15. Dubousset J, Charpak G, Skalli W et al (2010) EOS: a new imaging system with low dose radiation in standing position for spine and bone and joint disorders. J Musculoskelet Res 13:1-12

16. Faro FD, Marks MC, Pawelek J, Newton PO (2004) Evaluation of a functional position for lateral radiograph acquisition in adolescent idiopathic scoliosis. Spine (Phila $\mathrm{Pa}$ 1976) 29:2284-2289. doi:10.1097/01.brs.0000142224.46796.a7

17. Chaibi Y, Cresson T, Aubert B et al (2012) Fast 3D reconstruction of the lower limb using a parametric model and statistical inferences and clinical measurements calculation from biplanar X-rays. Comput Methods Biomech Biomed Engin 15:457-466. doi:10.1080/10255842.2010.540758

18. Mitton D, Deschênes S, Laporte $S$ et al (2006) 3D reconstruction of the pelvis from biplanar radiography. Comput Methods Biomech Biomed Engin 9:1-5

19. Humbert L, de Guise JA, Godbout B et al (2009) Fast 3D reconstruction of the spine from biplanar radiography: a diagnosis tool for routine scoliosis diagnosis and research in biomechanics. Comput Methods Biomech Biomed Engin 12:151-163. doi:10. 1080/10255840903081222

20. Quijano S, Serrurier A, Aubert B et al (2013) Three-dimensional reconstruction of the lower limb from biplanar calibrated radiographs. Med Eng Phys 35:1703-1712. doi:10.1016/j.medengphy. 2013.07.002

21. McDonald JH (2009) Handbook of biological statistics, 2nd edn. Sparky House Publishing, Baltimore

22. Lilliefors HW (1967) On the Kolmogorov-Smirnov test for normality with mean and variance. J Am Stat Assoc 62:399-402

23. Humbert L, Carlioz H, Baudoin A et al (2008) 3D evaluation of the acetabular coverage by biplanar Xrays or single anteroposterior Xray compared with CT-scan. Comput Methods Biomech Biomed Engin 11:257-262

24. Vaz G, Roussouly P, Berthonnaud E, Dimnet J (2002) Sagittal morphology and equilibrium of pelvis and spine. Eur Spine $\mathrm{J}$ 11:80-87

25. Schwab F, Lafage V, Boyce R et al (2006) Gravity line analysis in adult volunteers: age-related correlation with spinal parameters, pelvic parameters, and foot position. Spine (Phila Pa 1976) 31:E959-E967. doi:10.1097/01.brs.0000248126.96737.0f

26. Stokes IAF, Aronson DD, Ronchetti PJ et al (1993) Reexamination of the Cobb and Ferguson angles: bigger is not always better. J Spinal Disord 6:333-338

27. Kolta S, Le Bras A, Mitton D et al (2005) Three-dimensional X-ray absorptiometry (3D-XA): a method for reconstruction of human bones using a dual X-ray absorptiometry device. Osteoporos Int 16:969-976. doi:10.1007/s00198-004-1782-3

28. Duval-Beaupère G, Legaye J (2004) Composante sagittale de la statique rachidienne. Rev Rhum 71:105-119. doi:10.1016/j.rhum. 2003.09.018

29. Ryan DJ, Protopsaltis TS, Ames CP et al (2014) T1 Pelvic Angle (TPA) Effectively evaluates sagittal deformity and assesses radiographical surgical outcomes longitudinally. Spine (Phila Pa 1976) 39:1203-1210. doi:10.1097/BRS.0000000000000382

30. Gangnet N, Pomero V, Dumas R et al (2003) Variability of the spine and pelvis location with respect to the gravity line: a threedimensional stereoradiographic study using a force platform. Surg Radiol Anat 25:424-433. doi:10.1007/s00276-003-0154-6 